\title{
Reconceptualising health professions education in
}

AUTHOR:

Jimmy Volmink ${ }^{1}$

\section{AFFILIATION:}

${ }^{1}$ Faculty of Medicine and

Health Sciences, Stellenbosch

University, Stellenbosch,

South Africa

\section{CORRESPONDENCE TO: \\ Jimmy Volmink}

EMAIL:

jvolmink@sun.ac.za

\section{KEYWORDS:}

healthcare professionals;

community service;

interprofessional education;

community-oriented

primary care

\section{HOW TO CITE:}

Volmink J. Reconceptualising health professions education in South Africa. S Afr J Sci. 2018;114(7/8), Art. \#a0281, 2 pages. http://dx.doi. org/10.17159/sajs.2018/a0281

\section{PUBLISHED:}

30 July 2018
(C) 2018. The Author(s). Published under a Creative Commons Attribution Licence.

\section{Background}

In June 2018, the South African Minister of Health announced the gazetting of the National Health Insurance Bill - an important step towards achieving the government's aim of realising universal health care. The Academy of Science of South Africa's (ASSAf's) consensus study report ${ }^{1}$ on reconceptualising education and training of the health workforce, released in the same month, is therefore timely.

In recent years there have been several calls for changes in the way health professionals are trained around the globe. Most notable among these calls is the 2010 Lancet Commission report entitled: 'Health professionals for a new century: Transforming education to strengthen health systems in an interdependent world. '2 The Lancet report highlighted a number of failures in health professional education and recommended specific instructional and institutional reforms that are required to ensure that future healthcare professionals (HCPs) are 'fit-for-purpose'. Subsequently, the World Health Organization produced guidelines for transforming and scaling up HCP education and training, drawing on the findings of the Lancet Commission. ${ }^{3}$

Training institutions, educational groups and regulatory bodies in South Africa, have actively engaged with these global calls for reform. In 2012, ASSAf hosted a one-day workshop with key stakeholders to 'contextualise' the Lancet Commission's recommendations. The workshop culminated in ASSAf being asked to take the deliberations further, and the ASSAf Council responded by appointing a 10-person multi-professional panel to conduct a consensus study on the transformation of health professions education (HPE) in South Africa. The panel's brief was to consider a set of questions (produced by a task team) and to make evidence-based recommendations on how the transformational challenges, reflected in the pre-specified questions, could be addressed through interventions that are appropriate and feasible in the South African context.

\section{Conceptual framework}

As a point of departure, the ASSAf panel considered the goal of HPE to be 'the production of knowledgeable, competent, relevant and socially accountable HCPs who are capable of confidently and collaboratively promoting health and delivering quality health care in the context of universal health coverage'.

The conceptual framework adopted as a guide to the panel's deliberations comprised the following elements:

1. the health and higher education systems are interdependent;

2. population needs are determined by both social and individual determinants of health; these needs drive health system requirements, which, in turn, impact on the health professional mix, skills, competencies and attributes required by HCPs;

3. quantity, quality and relevance of HCPs are all important dimensions of education and training; and

4. iterative monitoring and evaluation, together with leadership and governance of HPE, are needed for transformation to be realised.

\section{Key transformational areas considered and recommendations of the panel}

The panel considered eight transformational areas for HPE in South Africa and made a total of 16 recommendations. Following is a summary of these, with further details, including the role players considered most appropriate for addressing the various issues, provided in separate concise and full versions of the report. ${ }^{1}$

\section{Student selection}

Currently, health sciences faculties in South Africa attempt to balance the tension between selection focused on student retention and success, and selection aimed at broadening access to training in order to achieve equity and redress. While good evidence exists that previous academic performance predicts academic success in undergraduate programmes, top performers do not necessarily turn out to be the best practitioners. The role of additional factors such as empathy, resilience, work ethic, ability to communicate and leadership qualities warrant attention in the discourse around student selection.

The report recommends evaluation of a broader set of selection criteria than those currently in use. It points to the need for rigorous research to determine which academic and non-academic selection criteria and student support measures best predict student success and promote the attainment of the desired graduate competencies in the South African setting. Academic development and support programmes targeted at both students and educators, and financial aid for needy students are considered essential for translating student access into retention and success.

\section{Scaling up the health workforce}

There is a shortage of HCPs in the country, most critically in the categories of medical practitioners, pharmacists and registered nurses. The main reason is that production of HCPs has not kept up with the increasing population growth, growing burden and complexity of disease, and expanding service workload in the public health sector.

The report recommends strengthening of public sector institutions to allow for the scaling up of HCP numbers. This scale-up will require additional training facilities and infrastructure, appropriately staffed clinical training 
platforms, collaboration with the private sector, and greater use of ICT to support training. Human resources for health planning will also need to be improved, ideally with the adoption of tracking and reporting of key human resources for health indicators. The report further recommends a multi-stakeholder approach to enhance health professional retention during studies, in the profession and in the country.

\section{Urban-rural maldistribution of HCPS}

The shortage of HCPs in rural and underserved areas in South Africa is a particularly critical issue. Despite $46 \%$ of the South African population residing in rural areas, only $12 \%$ of doctors and $19 \%$ of nurses practise in rural settings. Corresponding figures for medical specialists and allied health professionals are worse.

The report stresses the need for the selection and training of HCPs to be orientated towards addressing inequity and meeting the needs of the most underserved. It recommends that health science faculties prioritise applicants from rural and remote areas who meet the minimum academic criteria for selection, and that they ensure greater exposure to rural settings during training, with a stipulated minimum of clinical time spent in rural areas. The report additionally recommends 'community-oriented primary care' (a model in which primary health care is provided to a defined community based on assessed need and integration of primary care and public health practice) as a strategy to support service and learning. It also recommends that a monitoring system to track progress on practice in rural and underserved areas be designed and implemented.

\section{Team work}

Professional 'tribalism' is recognised as an important barrier to delivering effective health care. The Lancet commission identified 'interprofessional education and collaborative practice' (IPEPC) as an important catalyst for change in health care. IPEPC promotes the idea that transformative collaborative learning at undergraduate level will promote team work across professional boundaries in subsequent practice.

The ASSAf report supports the adoption of IPEPC and recommends that a multi-stakeholder, national working group be formed to develop and guide the implementation of a strategic plan for IPECP in order to ensure that it becomes sustainably embedded in South Africa. This plan should include a detailed stakeholder analysis and guidance for stakeholder engagement and buy-in. It should also delineate an IPECP competency framework and curriculum.

\section{Core competencies for South African HCPS}

Currently, the various professional and regulatory bodies each develop their own profession-specific competencies. There is a need to establish a set of core competencies for all professions focusing on IPEPC. The report recommends a hybrid competency-based education model that emphasises the process of learning and the achievement of learning outcomes. An Inter-Professional Regulatory Council working group would help to build consensus around a set of generic competencies for all HCPs.

\section{Faculty development}

Educators influence both the type and the quality of graduates produced, yet this aspect of the educational experience receives very little attention. There is a need for educators to be supported to become 'change agents'. The report highlights the importance of health professions educators being more responsive to both their internal learning community and the community beyond the institution. It suggests that this could be progressively realised through building a supportive institutional climate which values teaching, recruitment and integration of traditional and non-traditional faculty; developing competency for change agency; implementing transformative educational strategies; promoting adaptive education communities; and encouraging scholarship and reflection.

\section{Internship and community service}

Internship is currently a component of basic professional training for medicine (2 years), pharmacy (1 year) and psychology (1 year). While internship is legally part of professional training in South Africa it does not typically involve higher education institutions. Community service was first introduced for medical doctors in 1998 and has since been rolled out to include a number of HCP groups. Community service is intended to provide health services to rural and underserved areas and to allow young HCPs to further develop their skills and competencies. In practice, the focus has been largely on development of technical competencies, rather than attitudes, team work, community outreach and management skills. The current experience of internship and community service in South Africa could therefore be undermining the vision and intention of undergraduate health professions education.

The report proposes a shift from the mindset of interns and community service officers as the lowest levels of medical workers to one of active development of young professionals who are better equipped for public service. It recommends that universities take responsibility for education and professional development throughout the continuum from the undergraduate years through to internship (renamed postgraduate years 1 and 2) and community service (renamed postgraduate year 3 ). As the current 9 years is a long time for the production of a generalist doctor, the report recommends earlier differentiation with support for specialty training commencing in the community service year.

\section{Financing of HPE in South Africa}

It is the unanimous view of the panel that the success of the proposed transformation efforts will require proper financing of HPE. Longstanding shortcomings in the financing, planning and organising of HPE in South Africa largely arise from poor alignment of the interests of key stakeholders, such as the Department of Health, the Department of Higher Education and Training, and National Treasury. Poor coordination between governance at national and provincial levels is a further complicating factor.

The report recommends urgent action to improve the governance of health sciences funding, including through strengthening the capacity and accelerating the momentum of the Joint Health Sciences Education Committee. It considers the strengthening of governance structures and building a joint vision as critical initial steps, without which detailed costing and planning activities might not produce their full intended benefit. Improving human resources for health planning, resource allocation and budgeting should also receive priority. The report furthermore recommends the introduction of joint governance structures at institutional level, with strong consideration being given to reviving the concept of the academic health sciences complex. This model, if properly supported, has the potential to improve skills development, institutional governance and quality, and could form a strong basis for strengthening alignment of interests and more effective service delivery, as well as health sciences education. The model also has relevance in the context of greater institutional decentralisation required for the purchaser-provider split under National Health Insurance.

\section{Conclusion}

The ASSAf study on HPE provides a consensus view on how health professions education and training in South Africa could be reconceptualised and offers a roadmap for the way ahead. It is hoped that the panel's recommendations will help to consolidate current, and spur new efforts, to address the quantitative and qualitative shortfall in the health workforce, resulting in long-term benefits to the health of the nation.

\section{References}

1. Academy of Science of South Africa (ASSAf). Reconceptualising health professions education in South Africa. Pretoria: ASSAf; 2018. https://doi. org/10.17159/assaf.2018/0021

2. Frenk J, Chen L, Bhutta ZA, Cohen J, Crisp N, Evans T, et al. Health professionals for a new century: Transforming education to strengthen health systems in an interdependent world. Lancet. 2010;376:1923-1958. https:// doi.org/10.1016/S0140-6736(10)61854-5

3. World Health Organization (WHO). Transforming and scaling up health professionals' education and training: World Health Organization Guidelines 2013. Geneva: WHO; 2013. 